\title{
Atividade de Pesquisa e Formação de Gestores: A Contribuição do Projeto Conexão Local ${ }^{1}$
}

\author{
Ricardo Bresler ${ }^{2}$, Peter Spink ${ }^{3}$, Fernando Burgos P. dos Santos ${ }^{4}$ e Mario Aquino Alves ${ }^{5}$
}

RESUMO: O objetivo deste trabalho é descrever a experiência de quatro anos de existência do projeto Conexão Local da FGV-EAESP, a abordagem adotada e apresentar algumas das lições aprendidas. O projeto Conexão Local tem como meta aproximar os alunos da FGV-EAESP às diversas realidades brasileiras por intermédio de viagens de imersão que ocorrem no mês de julho de cada ano. Anualmente, são escolhidas diferentes experiências inovadoras com ênfase nas ações locais de melhoria e desenvolvimento, tanto na área pública quanto na área de organizações da sociedade civil, e os alunos - em duplas - passam um mês convivendo no dia a dia destas experiências. Distingue-se do Projeto Rondon, no qual busca-se disponibilizar o conhecimento a serviço da comunidade uma vez que o Conexão Local trilha o caminho inverso: quem vai para aprender são os estudantes e quem ensina são as experiências e os membros de uma comunidade inteligente (Dowbor, 2002).

PALAVRAS-CHAVE: Ensino e Pesquisa, Gestão Pública; Inovação Pública, Graduação.

ABSTRACT: This article describes FGV-EAESP's Conexão Local (Local Connection), a four-year old project that aims to introduce FGV-EAESP's undergraduate students to the different Brazilian realities through immersion trips every July. Every year, different innovative social cases - mostly focusing local incremental and developmental actions either from public or civil society organizations - are selected to be visited by a pair of students that will pass one month observing and getting acquainted to the everyday life of the subjects that carry on those experiences. This project is different from the Federal Government "Projeto Rondon”, which aims to provide applied knowledge to the community through trained students. Conexão Local trails an opposite path: the students learn from the experiences and they are taught by members of an intelligent community (Dowbor, 2002)

Keywords: Public Management, Research and Learning; Public Innovation , undergraduate Program.

\footnotetext{
${ }^{1}$ Os autores agradecem a Veronika Paulics pela revisão do texto e assumem a responsabilidade por eventuais equívocos que tenham persistido

${ }^{2}$ Professor da Escola de Administração de Empresas de São Paulo da Fundação Getulio Vargas e Professor.Endereço para correspondência: Centro de Estudos de Administração Pública e Governo (CEAPG)- R. Itapeva, 474, 11 andar. CEP 01332-000

${ }^{3}$ Professor da Escola de Administração de Empresas de São Paulo da Fundação Getulio Vargas e Professor.Endereço para correspondência: Centro de Estudos de Administração Pública e Governo (CEAPG)- R. Itapeva, 474, 11º andar. CEP 01332-000.

${ }^{4}$ Mestre em Administração Pública pela EAESP FGV. Pesquisador do Centro de Estudos de Administração Pública e Governo (CEAPG). Endereço para correspondência: Rua Itapeva, 474, 11 ${ }^{\circ}$ andar. CEP 01332-000.

${ }^{5}$ Professor da Escola de Administração de Empresas de São Paulo da Fundação Getulio Vargas e Professor.Endereço para correspondência: Centro de Estudos de Administração Pública e Governo (CEAPG)- R. Itapeva, 474, $11^{\circ}$ andar. CEP 01332-000
} 


\section{Introdução}

A Escola de Administração de Empresas de São Paulo da Fundação Getúlio Vargas (FGVEAESP), como as demais Escolas, Faculdades e Universidades participantes da ANPAD, tem uma preocupação constante com a pesquisa e a investigação. No caso específico da FGV-EAESP, desde cedo na sua história foram criados mecanismos internos de apoio à pesquisa, utilizando principalmente uma sobretaxa nas suas atividades de educação continuada para executivos. O resultado foi a criação de seu Núcleo de Pesquisa e Publicações (agora GVpesquisa) e uma modalidade simples de apoio à investigação consistindo em um pequeno adicional salarial e uma pequena ajuda de custos para os professores. Em contrapartida, estes se comprometem em publicar os resultados das investigações e submetê-las a uma avaliação.

Neste processo de financiamento, é comum que professores solicitem apoio para contratar monitores e assistentes de pesquisa oriundos, respectivamente, dos cursos de graduação e pós-graduação. A Escola também participa do Programa PIBIC do CNPq não somente administrando as bolsas mas também com uma alocação complementar de bolsas para alunos não contemplados com os recursos do CNPq. Os orientadores do PIBIC são pesquisadores da Escola com produção científica consolidada.

Esta postura e estas atividades - mesmo com alguns mecanismos diferenciados - não são uma novidade entre os principais programas de ensino e pesquisa em administração no País. Todas as Escolas, Faculdades e Universidades representadas na Associação Nacional de Pesquisa e Pós-Graduação em Administração buscam apoiar a pesquisa e estão preocupadas com a produção de conhecimento útil e aplicável nos contextos organizativos brasileiros. Esta preocupação tampouco se restringe aos cursos de Pós, mas também se estende, ou se inicia, nos cursos de graduação. Sabemos, todavia, que a área de administração, seja de empresas, pública ou do terceiro setor, tem uma forte vocação profissional e que inevitavelmente a grande maioria de graduandos irão para o mundo das atividades de gestão. Em muitos cursos de graduação na área - e EAESP não era exceção o resultado foi remeter a discussão e da prática da pesquisa na graduação para um terceiro, quando não quarto plano, suficiente apenas para garantir o atendimento à pequena proporção dos interessados que optariam posteriormente por uma carreira acadêmica de docência e pesquisa.

CADERNOS GESTÃO PÚBLICA E CIDADANIA, V. 13, N.52 - JAN./JUNHO 2008 
Nos últimos anos esta situação mudou significativamente. Além do aumento da demanda por docentes qualificados, houve uma grande redução nos prazos dos cursos de mestrado, deixando pouco tempo para "aprender" as artes da pesquisa investigativa. O PIBIC, neste contexto, cresceu em importância, especialmente para o jovem que quer se projetar numa carreira acadêmica. Igualmente as demandas das agências de avaliação nacionais e internacionais tornam a produção acadêmica um eixo fundamental, e não eventual, na avaliação de cursos e instituições.

A mudança mais significativa, no entanto, gostaríamos de argumentar, não veio deste quadrante. Pelo contrário, veio justamente do quadrante oposto onde a maioria dos egressos busca se fixar, ou seja, na carreira profissional. A compreensão da contribuição da pesquisa ao dia a dia das organizações e a capacidade de conviver com a pesquisa torna-se, cada vez mais, parte das habilidades de qualquer gestor, seja em relação às decisões empresarias, às políticas públicas ou às ações de organizações do terceiro setor. A capacidade de produzir relatórios analíticos, agregando dados de diferentes tipos, tornou-se parte da atividade diária dos gestores. Não é acidental, portanto, que haja um aumento dos cursos de graduação que exigem trabalhos de conclusão de curso de peso e que a monografia tenha se tornado quase obrigatória não somente nos mestrados profissionais, mas de muitos dos cursos de especialização tipo MBA executivo.

Cinco anos atrás, a FGV-EAESP iniciou um extenso processo de discussão e debate sobre o formato de seus cursos de graduação, reconhecendo que muita coisa havia mudado desde seu último “repensar”, dez anos antes. A partir desta discussão e também pelo interesse crescente de alunos e professores em ampliar as possibilidades de pesquisa na área de graduação, foram introduzidas duas novas possibilidades de convivência com o mundo de investigação científica. O conjunto como um todo foi sistematizado dentro do que se passou a chamar de Programa de Introdução à Pesquisa (PIP). O PIP consiste atualmente em quatro oportunidades diferentes para os alunos se envolverem com a investigação científica e a produção de conhecimento. A primeira, conhecida como Conexão Local é o foco deste trabalho e consiste na experiência intensiva de um mês de convivência com o mundo da inovação social no âmbito público. Esta atividade está orientada para alunos do segundo, terceiro, quarto ou quinto semestres e foi influenciada pelo programa pioneiro de convivência com o mundo da ação social desenvolvido em termos de residência social pelo 
Programa de Gestão Social da Universidade Federal da Bahia (UFBA). A segunda, a residência em pesquisa, aberta prioritariamente para alunos no quarto, quinto e sexto semestres, tem como objetivo permitir conhecer o cotidiano das atividades de pesquisa realizadas nos diferentes centros de estudos e pesquisa da EAESP. A terceira, o Programa Institucional de Bolsas de Iniciação Científica (PIBIC) está orientado prioritariamente para alunos do sexto, sétimo e oitavo semestres interessados em elaborar um projeto próprio de pesquisa e investigação. A quarta atividade, que pode ser feita em qualquer momento durante o curso, é a possibilidade de trabalhar como monitor de um dos professores pesquisadores da EAESP. Em todos os casos os alunos recebem uma bolsa de estudos e, no caso específico do Conexão Local, as despesas de viagem e hospedagem também são custeadas pelo fundo de pesquisa.

A experiência de quatro anos do Projeto Conexão Local (2005 - 2008) e a imersão de 68 alunos em 34 diferentes experiências inovadoras do norte ao sul do País demonstram que esta introdução à arte de pesquisa, compreendida como atividade interativa e investigativa junto com o engajamento dos jovens nas possibilidades de um agir público inovador, forma não somente melhores gestores e pesquisadores, mas também cidadãos.

O objetivo deste trabalho é descrever a abordagem adotada e apresentar algumas das lições aprendidas nestes quatro anos. Não pretendemos argüir dedutivamente a partir de uma postura teórica presumida, porque não foi isso o caminho. Havia um pouco de tentativa e erro e, principalmente o pressuposto da importância de uma prática mais horizontal de pesquisa e de ação. Uma comparação possível seria o Projeto Rondon, do qual o Conexão se diferencia por não se dedicar a levar conhecimento para a comunidade, por considerar que são os estudantes que irão aprender com as experiências e os membros de uma comunidade inteligente (Dowbor, 2002).

\section{O Projeto Conexão Local}

O objetivo do projeto Conexão Local é aproximar os alunos da FGV-EAESP às diversas realidades brasileiras por intermédio de viagens de imersão que ocorrem no mês de julho de cada ano. Pretende-se favorecer o conhecimento prático de técnicas de gestão em regiões e contextos os mais variados e complexos; incentivar atitudes mais humanas e colaborativas, visando a formação de futuros administradores com uma consciência cidadã, pró-ativa e

CADERNOS GESTÃO PÚBLICA E CIDADANIA, V. 13, N.52 - JAN./JUNHO 2008 
socialmente empreendedora; promover a troca de saberes entre alunos, gestores públicos, comunidades, associações, empresários e técnicos locais e incentivar reflexões e discussões em torno de questões e realidades concretas. Anualmente, são escolhidas diferentes experiências inovadoras na área pública ou na área de organizações da sociedade civil com ênfase nas ações locais de melhoria e desenvolvimento e os alunos - em duplas - passam um mês convivendo no dia a dia destas experiências.

As atividades de imersão são precedidas por uma preparação que envolve seminários sobre o dia a dia dos municípios e sobre as diferentes territorialidades brasileiras, bem como discussões sobre métodos de pesquisa de campo. Os alunos são acompanhados nos primeiros dias por um supervisor (mestrandos, doutorandos ou recém-doutores) que não apenas monitora as atividades, mas também ajuda na busca de soluções para eventuais problemas de pesquisa ou de aprofundamento do contato com a equipe local. O supervisor, quando possível, ainda retorna ao local visitado no final do período de campo para a realização de uma discussão da qual participam os alunos e os representantes da experiência que está sendo visitada.

Ao final do período de imersão, cada dupla prepara um relatório e posteriormente alunos, tutores e gestores das atividades visitadas se encontram para um seminário, do qual também participa a comunidade da EAESP.

No início, as experiências a serem visitadas eram selecionadas do banco de dados do Programa Gestão Pública e Cidadania, criado em 1996 para analisar e disseminar práticas inovadoras entre os governos sub-nacionais brasileiros (Estados Municípios e Povos Indígenas) para o fortalecimento da cidadania e a melhoria da qualidade de vida coletiva. $\mathrm{O}$ Programa focaliza experiências - políticas, programas, projetos ou atividades - que têm um impacto positivo no fornecimento de serviços públicos e que podem ser reproduzidas em outras localidades, de acordo com as particularidades de cada lugar, e que utilizem recursos e oportunidades de maneira responsável, contribuindo para a ampliação do diálogo entre a sociedade civil o os agentes públicos.

Com o aumento da visibilidade do programa, e considerando os distintos interesses dos estudantes que se interessam pela investigação acadêmicas, as experiências atualmente visitadas são selecionadas também a partir das contribuições de outros Centros de Estudo da EAESP e não somente do Centro de Estudos de Administração Publica e Governo. 


\section{Os Alunos e as Experiências}

O perfil dos estudantes de graduação que o projeto procura é especificado no edital de seleção ${ }^{6}$ :

- Interessados em desenvolver o seu potencial investigativo;

- Interessados em conhecer práticas de gestão in loco e capazes de aprender com os gestores, técnicos, servidores, parceiros e beneficiários da experiência e com a realidade observada;

- Com potencial de se relacionarem com as pessoas envolvidas nos projetos a serem vivenciados;

- Com capacidade de auto-organização e de adaptar-se em situações diferentes das do seu cotidiano;

- Interessados em vivenciar ações locais inovadoras, que vêm sendo desenvolvidas com êxito e apresentam soluções concretas no enfrentamento da pobreza, na oferta de serviços públicos e no fortalecimento da democracia.

Desde o início do projeto, a preocupação da equipe foi a de selecionar alunos com “os pés no chão", mesmo que isso implicasse em reduzir o numero de experiências a serem visitadas. De ano para ano o numero de estudantes interessados aumentou a ponto de, na ultima seleção, participarem 24 alunos.

Do lado das experiências, o importante é que sejam experiências de ação pública local, que contribuam com o fortalecimento da cidadania, da democracia e da ampliação do acesso a direitos. Além disso, as experiências devem ter substância e disponibilidade: com gestores, servidores, técnicos, parceiros e beneficiários que tenham acumulado uma experiência que possa contribuir para a formação dos estudantes, dispondo de conteúdo a ser pesquisado ao longo de três semanas de investigação, nas quais alguém (o gestor, por exemplo) possa recepcionar e co-orientar com o supervisor as visitas de campo. Para cada experiência há sempre um informante-chave que é o interlocutor no campo.

\footnotetext{
${ }^{6}$ Edital de seleção da edição de 2008, disponível em: http://www.fgvsp.br/conexaolocal
} 
O Quadro 1 apresenta a relação dos 34 programas e projetos visitados nestes quatro anos do projeto. Detalhes maiores sobre a maior parte delas são disponíveis no site do Centro de Estudos de Administração Pública e Governo (www.fgv.br/ceapg) e do projeto (www.fgvsp.br/conexaolocal).

Quadro 1 - Relação das experiências visitadas por estado e edição:

\begin{tabular}{|c|c|c|}
\hline Estado & Programa & Edição \\
\hline \multirow{2}{*}{$\mathrm{AC}$} & Programa Floresta Estadual do Antimary & 2005 \\
\hline & Casa Rosa Mulher & 2008 \\
\hline AL & Fundo para o Desenvolvimento da Agricultura Familiar & 2005 \\
\hline AP & Programa Castanha & 2006 \\
\hline \multirow{3}{*}{ BA } & APAEB & 2005 \\
\hline & Rede Pintadas & 2006 \\
\hline & Produção Sisaleira - Valente & 2007 \\
\hline \multirow{5}{*}{ CE } & Programa de Saúde da Família - Sobral & 2006 \\
\hline & Projeto Pingo D'Água & 2006 \\
\hline & Banco Palmas & 2007 \\
\hline & Crediamigo & 2008 \\
\hline & Projeto São José & 2008 \\
\hline \multirow{2}{*}{ MA } & CINPRA - Consórcio Intermunicipal de Produção e Abastecimento & 2005 \\
\hline & CEAPE & 2007 \\
\hline \multirow{2}{*}{ MG } & Política Municipal de Abastecimento e Seguraça Alimentar & 2005 \\
\hline & Gestão de Resíduos Sólidos & 2006 \\
\hline MS & PROVE - Programa de Verticalização da Pequena Produção Agrícola & 2006 \\
\hline \multirow{4}{*}{ PA } & Projeto Ação Comunitária em Arte e Ofício & 2006 \\
\hline & Programa Saúde e Alegria - Santarém & 2007 \\
\hline & Experiências coordenados pelo Escritório Zonal do Unicef & 2008 \\
\hline & Desenvolvimento Local de Juruti & 2008 \\
\hline $\mathrm{PB}$ & Programa de Fortalecimento da Cadeia Produtiva do Algodão Colorido & 2006 \\
\hline \multirow{4}{*}{$\mathrm{PE}$} & ETAPAS e Programa de Saúde Ambiental & 2005 \\
\hline & Programa Mãe Canguru & 2006 \\
\hline & Programa Recife Multicultural - Recife & 2007 \\
\hline & Projeto Bonequinhas Solidárias - Gravatá & 2007 \\
\hline PI & Programa Municipal de Educação & 2007 \\
\hline PR & Economia Solidária - Londrina & 2007 \\
\hline RJ & Piraí Digital & 2007 \\
\hline $\mathrm{RN}$ & PROCAP & 2008 \\
\hline $\mathrm{RR}$ & Projeto Crescer & 2005 \\
\hline RS & Desenvolvimento Local - Tupandi & 2007 \\
\hline SC & Consórcios Quiriri e Lambari & 2008 \\
\hline SP & Desenvolvimento Sustentável do Vale do Ribeira & 2008 \\
\hline
\end{tabular}

Fonte: autores (2008) 
No início, discutia-se a possibilidade de duas imersões por ano, mas tanto o trabalho de preparação quanto o ciclo brasileiro da gestão pública rapidamente demonstraram que realizar as imersões uma vez ao ano e em julho era mais viável. Entretanto o trabalho de fato, em termos de cronograma, começa em outubro com os preparativos da coordenação e da equipe administrativa do GVpesquisa. A coordenação começa o trabalho preparativo para a realização da edição do ano seguinte. O processo de seleção dos estudantes ocorre no início de cada ano e a definição dos trios se dá até o final do mês de abril, para que os meses de maio e junho sejam dedicados à preparação para a visita de campo e para a formação das equipes. A Coordenação do projeto trabalha a preparação por dois caminhos: na relação com todos os envolvidos; e junto aos supervisores para apoiar o trabalho específico de cada trio. As atividades com todos os envolvidos consistem basicamente do exercício de algumas ferramentas básicas para a pesquisa de campo, do que é uma pesquisa de campo, do que precisa ser observado, de como se preparar para a visita, momentos nos quais são reafirmados os objetivos e princípios do projeto.

A preparação de cada trio se dá por meio da capacitação do supervisor para o trabalho naquela experiência específica, que implica um território e uma temática própria. Recentemente, o trabalho do supervisor foi ampliado e é o supervisor quem faz a apresentação das especificidades da experiência a ser visitada. O trabalho pré-campo é importante para que os estudantes se familiarizem com o que irão encontrar naquela experiência em particular e, também, porque é por meio dessas atividades que os trios vão se conhecendo (freqüentemente os estudantes não se conhecem até esse momento). Essa aproximação é fundamental para o convívio que eles terão ao compartilhar essa experiência de investigação, imersos num cotidiano.

O supervisor acompanha as duplas em campo durante a primeira semana de pesquisa período no qual o supervisor apresenta a dupla aos responsáveis pela experiência e, junto com o informante-chave, desenha a agenda de pesquisa. Na edição em Julho 2008, foi estabelecido o princípio de distanciamento in loco, ou seja, no período final dessa primeira semana, o supervisor deixa a dupla sozinha no trabalho de campo, encontrando-se com ela no final do dia para que as dúvidas, dificuldades e apreensões sejam conversadas pessoalmente. Com a sua partida na semana seguinte, o trabalho de supervisão passa a ser o acompanhamento à distância, até o retorno das duplas ou, quando há possibilidade, o 
retorno ao campo do supervisor. O relatório é escrito pela dupla durante os meses de agosto e setembro, com orientação do supervisor, e é apresentado em novembro como uma das atividades do "Dia da Pesquisa” da FGV-EAESP.

\section{A construção do Projeto Conexão Local}

As primeiras conversas e idéias que fomentaram o projeto, tal qual existe atualmente, ocorreram no âmbito do Centro de Estudos em Administração Pública e Governo da EAESP, inspirados pela experiência de intercâmbio da EAESP com mais de 100 alunos por semestre vindos de mais de 80 diferentes universidades do mundo - e estudantes da EAESP indo para outros países - e também pelos estudos feitos no Centro sobre as experiências das escolas rurais e indígenas brasileiras que trabalhavam com a pedagogia de alternância (Laczynski, 2000).

No que se refere ao intercâmbio, reconhecia-se a importância dessa vivência trans-cultural para a formação dos estudantes de graduação que permitia, além do aprendizado dos conteúdos aprendidos em sala de aula, a vivência em uma outra cultura e o convívio com pessoas de outras nacionalidades, contribuindo para o amadurecimento e a formação dos nossos estudantes.

Por outro lado, o contato com escolas que adotam a pedagogia de alternância chamava a atenção para as virtudes e potencialidades de um meio de ensino-aprendizagem no qual os estudantes alternam períodos em sala de aula com períodos no qual os estudantes acompanham os desafios do seu cotidiano familiar ou profissional ${ }^{7}$. Isso servia como provocação (e ainda serve) de como se poderia incorporar esse princípio, e aproveitar esse potencial de aprendizagem, na formação de futuros gestores. O resultado era, conforme a expressão, uma idéia simples que encontrou o seu momento.

Para servir de solo para esses insumos, o Centro tinha disponível a rede que se formou em torno do Programa Gestão Pública e Cidadania. Além das visitas de campo que ocorriam para os ciclos de premiação e outros projetos, realizávamos seminários e fóruns de discussão nos quais fomos fortalecendo os vínculos com diversos gestores e técnicos de

\footnotetext{
${ }^{7}$ No caso da escola de alternância, durante 15 dias os estudantes ficam em casa, em geral uma pequena propriedade rural, colaborando com o plantio, a colheita, ou com o cuidado com os animais, aplicando e discutindo com sua família os novos métodos aprendidos na escola. Por outro lado, os 15 dias na escola permitem refletir sobre as técnicas tradicionais, buscando superar suas limitações, discutir as dificuldades do dia a dia, etc.
} 
governo que se tornavam interlocutores especiais para que nossos estudantes pudessem ir conhecer a administração pública que efetiva diferentes administrações públicas locais.

Com apoio mais ou menos formal do Centro, três grupos de estudantes realizaram o que podemos considerar os três pilotos da pré-história do Projeto Conexão Local. Tinham, em comum, a iniciativa dos estudantes de graduação instigada com a idéia de uma outra gestão local mas querendo ver in loco se as experiências discutidas em sala de aula eram de fato possíveis. Em uma delas, um grupo de quatro estudantes do Curso de Graduação em Administração Pública (CGAP) foi apresentado aos técnicos do governo do Estado do Amapá e, sem vinculo formal com a FGV, visitaram alguns projetos do governo estadual. Em janeiro de 2003, com apoio institucional do Centro, uma dupla de estudantes do CGAP foi formada para pesquisar as experiências de gestão local do município de Icapuí, CE (Lotta \& Martins, 2003). Na passagem de 2003-04 foi formada uma expedição, da qual fazia parte um estudante do CGAP, que percorreu todo o Rio São Francisco, pesquisando os municípios que tinham experiências inscritas no banco de dados do programa GPC .

Todas essas iniciativas representaram uma oportunidade de aprendizagem para os estudantes e para a Coordenação do Centro, servindo de base para o projeto que, gradativamente, começou a se desenrolar e a se institucionalizar cada vez mais, com o envolvimento de cada vez amis centros de estudos e experiências. Por exemplo, o Centro de Estudos de Microfinanças entrou com a indicação da experiência do Banco Palmas em Fortaleza e continua com outras indicações. O Centro de Estudos de Sustentabilidade também com uma serie de oportunidades de avaliação de impactos ecológicas sendo coordenadas por municípios da Amazônia. Tudo indica que o caminho do projeto é de envolver, gradualmente, outros Centros de Estudos num processo que busca, mais que o compromisso formal, o diálogo e o envolvimento direto nas atividades de campo.

\section{O projeto Conexão Local como atividade de pesquisa}

Conforme comentado anteriormente, o projeto Conexão Local faz parte do Programa de Iniciação a Pesquisa (PIP) da FGV-EAESP, que abriga todas as oportunidades de pesquisa direcionadas aos estudantes de graduação. Compõem o PIP, além do Conexão Local, a

\footnotetext{
${ }^{8}$ O grupo visitou 20 cidades de 6 diferentes unidades da federação. Ver documentário “Na Margem do Velho Chico" direção de Tatiana Travisani, São Paulo, 2006
} 
Residência em Centros de Pesquisa e o Programa Institucional de Bolsas de Iniciação à Pesquisa (PIBIC).

Dentro dessas opções, o projeto Conexão Local é tratado como a porta de entrada preferencial nas atividades de pesquisa. Não é uma entrada obrigatória e nem há uma estrutura rígida mas é o caminho sugerido como o mais adequado. Os princípios que orientam esse fluxo ideal (CL $\rightarrow$ residência $\rightarrow$ PIBIC), valorizam o movimento pelo qual o aprendizado se dá num primeiro momento contato com o "objeto" concreto (a realidade da gestão pública local e a diversidade da realidade brasileira). A partir disso, o conhecimento pode ser aprofundado pela descoberta de como um campo específico é trabalhado - por meio do convívio com os que trabalham em investigações aplicadas neste campo - para depois assumir um papel mais autônomo como pesquisador independente.

Assim, o estudante da graduação começaria por vivenciar uma experiência administrativa, aprendendo com as pessoas (gestores, técnicos, servidores, parceiros membros de comunidades e beneficiários) que efetivam práticas de gestão que promovem a democracia para, a partir do contato com essa experiência concreta, trabalhar junto com pesquisadores mais seniores - professores e estudantes de pós-graduação - e aprender como é o ofício da pesquisa na academia. Acreditamos que efetivando esse percurso, os estudantes da graduação desenvolvem um ótimo potencial para formular e encaminhar seu projeto de iniciação científica. Para os supervisores, por sua vez, o projeto Conexão Local é uma atividade de investigação que reforça a importância da pesquisa de campo, tanto na coleta de dados a partir das diferentes vozes presentes em cada localidade, quanto no constante descortinar da diversidade da realidade brasileira nas suas dimensões quantitativas e qualitativas. Para eles também é uma introdução monitorada (pela presença constante dos coordenadores acadêmicos) à prática de orientação. Para ambos, representa uma oportunidade de investigação em que se reforça a importância dos saberes locais (Geertz, 2003, Lotta 2006), por meio da possibilidade de acompanhar as forças e dinâmicas de cada localidade na construção das experiências de gestão pública que são pesquisadas. 


\section{Um Programa de Formação}

Para os estudantes da Graduação, a experiência de preparação, imersão e elaboração de relatórios - alem de muita discussão - é uma oportunidade ímpar de complementar a sua formação como futuros gestores e cidadãos. Por meio da vivência de processos de gestão, junto aos gestores, técnicos, servidores, parceiros e beneficiários diretos e indiretos, os estudantes de graduação podem acompanhar o movimento e o processo dinâmico pelo qual as políticas e ações públicas são elaboradas, implantadas e ajustadas ao longo do tempo e reconhecer os inevitáveis conflitos e contradições presentes. Nesse sentido, o Conexão Local privilegia uma formação de gestores que compreendam os processos de mudança organizacional como um movimento dinâmico e contínuo, ao invés de uma visão que proclame que uma boa mudança é algo que somente é trabalhado em um gabinete e imposta para a transformação de uma determinada realidade organizacional; aprendizagem esta que vale tanto para a área empresarial quanto para a área pública. Infelizmente ainda se presume em muitos lugares que as estruturas, normas e deliberações burocráticas são capazes, por si só e sem ações complementares, de transformar qualquer aspecto da realidade.

A experiência do Conexão Local demonstra a importância de uma abordagem pela qual não se espera que a estrutura por si só seja capaz de mudar a realidade, mas que se pode administrar estruturas para poder sustentar as mudanças que os processos sociais, econômicos, políticos e culturais foram capazes de gerar. A diferença parece estar menos na natureza dos processos de gestão e de mudança e mais no que destacamos por meio do nosso olhar, da abordagem que adotamos - nesse sentido o projeto Conexão Local pode ser entendido como um programa de formação que visa trabalhar o olhar dos gestores. Dessa forma, os estudantes têm a oportunidade de acompanhar como os gestores, técnicos, servidores e parceiros criam espaços nos quais a transformação da realidade organizacional se torna possível. Mais do que acompanhar administradores que tentam impor a sua vontade independente do que pensam os outros, nossos estudantes têm a oportunidade de acompanhar o perene processo de negociação dos significados com os envolvidos no processo administrativo, gestores e não gestores.

Assim, uma experiência de imersão como esta complementa os processos tradicionais de ensino-aprendizagem, permitindo que os estudantes possam entrar em contato, aprender e

CADERNOS GESTÃO PÚBLICA E CIDADANIA, V. 13, N.52 - JAN./JUNHO 2008 
exercitar diversas ferramentas administrativas essenciais para o desempenho da gestão, por meio de uma abordagem que os exponha aos processos cotidianos da gestão, que os exponha às pessoas que efetivam (ou pelo contrário, que seriam capazes de obstruir) planos e objetivos organizacionais. Importante aqui é de enfatizar que esta aprendizagem é válida para qualquer situação organizativa. Participam do Conexão Local alunos de ambos os cursos de graduação da Escola (empresas e pública) como também os supervisores são escolhidos de ambos os programas de pós-graduação e o fato de as experiências visitadas serem da área pública é, em parte, uma conseqüência da maior disposição dos atores organizacionais da área pública para abrir seu dia a dia aos estudantes universitários. Há poucas empresas dispostas a abrir seus processos de planejamento e implementação de projetos com a mesma franqueza, ou que permitiriam um acesso tão amplo a seus empregados, fornecedores e clientes.

Para os supervisores, o projeto Conexão Local possibilita o exercício do trabalho de orientação em toda a sua amplitude. Nos trabalhos de investigação pré-campo, o exercício é o de orientar o mapear as fontes de informação, sistematizar dados, relatos e análises a respeito da experiência, do território e da temática a ser pesquisada, com o intuito de preparar para a pesquisa de campo. Durante a visita de campo, principalmente durante a primeira semana na qual o supervisor encontra-se em campo, o supervisor tem a oportunidade de acompanhar as dificuldades, dúvidas e anseios dos jovens pesquisadores, orientando-os tanto em relação aos aspectos da pesquisa em si, quanto aos dilemas de ser pesquisador. No retorno da pesquisa de campo, o supervisor exercita o papel de orientador na fase monográfica, acompanhando e supervisionando a produção do relatório da dupla que acompanhou. Com essas atividades, o projeto pretende contribuir com a formação de novos professores-orientadores.

O contato com experiências de boas gestões públicas permite também desconstruir alguns mitos que rondam os assuntos ligados à administração pública e ao Estado de forma geral. Para os estudantes que têm preconceito em relação a tudo que venha do Estado, é uma oportunidade de conhecer e conviver com gestores, técnicos e servidores públicos que trabalham com seriedade e comprometimento, com gente competente e que administra os recursos disponíveis em busca do fortalecimento do estado democrático e da efetividade administrativa. Para aqueles que já têm o ideal de trabalhar pelo fortalecimento dessa 
administração pública, mas que muitas vezes acreditam que isso seja fácil e que só dependa de um pulso (ou de um verbo) forte, é uma oportunidade de aprender com quem já está nesta estrada as dificuldades de gerir essa mudança, aprendendo com eles a lidar com resistências e interesses distintos, sobre como construir espaços para a negociação e viabilização de projetos.

Um exemplo ocorrido na experiência Casa Rosa Mulher, um importante projeto na área de violência de gênero em Rio Branco (AC), mostra como o convívio com esses profissionais pode mostrar, na prática, os desafios de implementação de um projeto. Seguindo a orientação da Coordenadoria (municipal) da Mulher, todas as profissionais que atuam na Casa Rosa Mulher não devem envolver questões religiosas nos assuntos profissionais. Trata-se de manter o órgão público como instituição laica. No entanto, segundo a coordenadora da Casa, é muito comum que as educadoras das oficinas oferecidas tenham momentos de bate-papo, com as mulheres atendidas pela casa - que em sua maioria, encontram-se em situação de violência. E é nesses momentos que as educadoras esquecem a orientação laica e emitem suas opiniões pessoais, carregadas de convicções religiosas. Como a maioria das educadoras é evangélica, às vezes sugerem às mulheres vítimas de violência que perdoem os maridos agressores, em nome da preservação do casamento.

Ao relatar e discutir essa situação, foi possível mostrar aos estudantes os dilemas que a Street Level Bureaucracy (Lipsky1980) traz para os formuladores das políticas. Independentemente de optarem por trabalhar na área pública ou privada, certamente foi importante para a formação dos alunos esse exemplo e as reflexões que ele proporcionou sobre os desafios presentes nas etapas de implementação de um projeto.

É nestes momentos, e também no convívio diário nas comunidades, praças, ruas e rios do País, que emerge uma outra contribuição importante para a formação dos estudantes. Na EAESP, como em outras universidades que se destacam pela qualidade de suas atividades de pesquisa, os estudantes da graduação são em sua maioria oriundos das classes médias altas. De repente entram em contato, para alguns pela primeira vez, com pessoas oriundas de outras classes sociais. Além de entrar em contato - e aqui é uma das marcas importantes da preparação para a visita - os estudantes descobrem que têm muito com pessoas que, na maior parte das vezes, não têm diplomas universitários, mas que são detentoras de outros saberes e competências construídas na prática diária.

CADERNOS GESTÃO PÚBLICA E CIDADANIA, V. 13, N.52 - JAN./JUNHO 2008 


\section{A importância do dialogo}

Vivemos num País em que diferentes se encontram razoavelmente apartados, dos diferentes universos que pessoas de classes socioeconômicas distintas habitam, aos diferentes ethos de administradores e de administrados, pela ignorância mútua entre estudantes de graduação e de pós-graduação, pela indiferença que muitos saberes e práticas universitárias mantém em relação ao cotidiano da maior parte da população e a diversidade de saberes locais: muitas vezes parece que os grupos habitam ilhas diferentes e que o país longe de ser um território é nada mais de um arquipélago desconecto. Enquanto atividade de pesquisa que visa complementar a formação de gestores, o projeto Conexão Local procura intervir nesse cenário propiciando condições para que diferentes diálogos possam ser estabelecidos.

Ao criar trios nos quais uma dupla de estudantes de graduação é supervisionada por alguém ligado aos programas de pós-graduação, o projeto permite aos recém-entrados na faculdade conhecer quem já se iniciou na investigação há mais tempo, e coloca potenciais futuros orientadores (muitos já desempenham a docência) em contato mais próximo, intimo e intenso, com os jovens graduandos.

Ao privilegiar esse perfil de supervisor e ao recrutá-lo junto aos diferentes centros de estudo da FGV-EAESP, essa aproximação pode ir além do conhecer um indivíduo. Pode levar a conhecer o processo coletivo por trás dos grupos de pesquisa, e permite uma aproximação entre diferentes saberes dos Centros de Estudo fortalecendo a cultura investigativa da Escola com um todo, contribuindo para uma discussão mais orgânica em relação aos diferentes processos sociais, econômicos, políticos e culturais presentes na realidade e, principalmente, na diversidade das realidades que compõe o contexto nacional.

\section{Ampliando a rede}

No ciclo de 2008, após a formação de todos os trios e o início dos trabalhos pré-campo, um estudante da graduação ficou impossibilitado de continuar no projeto. Havíamos investido na consistência e seriedade do nosso processo seletivo e não encontrávamos alguém que pudéssemos chamar para cobrir essa vaga, nem tínhamos tempo hábil para efetivarmos outro processo seletivo. Consideramos a possibilidade de convidar um participante do ano anterior, mas descartamos essa hipótese porque poderia verticalizar a relação da dupla, uma vez que um dos participantes já teria experimentado a vivência no campo e, caso 
convidássemos um estudante que não havia participado do Conexão, corríamos o risco de jogar fora o investimento (para as próximas edições) que fizemos no processo seletivo. Cogitamos também a possibilidade de quebrar o principio das duplas no campo, criando uma experiência em que alguém fizesse o trabalho sozinho, ou incorporando a estudante que ficou sem par a alguma das duplas constituídas - a pesquisa individual não parecia atraente pela impossibilidade do importante diálogo que a dupla cria para compartilhar o que vai descobrindo. Um trio também representava um risco de haver um terceiro membro, que poderia ser excluído.

Diante dos dilemas que esse imprevisto trouxe, a saída que encontramos foi a de ampliarmos os diálogos, envolvendo colegas na Universidade Federal de Acre (a experiência era o Projeto Casa Rosa Mulher). Três professores ${ }^{9}$ formaram um comitê de seleção que escolheu e indicou uma estudante para compor a primeira dupla interuniversitária do projeto Conexão Local. Em novembro, por ocasião do Dia da Pesquisa na FGV-Eaesp, essa estudante virá a São Paulo para apresentar o relatório da visita que realizaram e também para dar continuidade à pesquisa, visitando programas similares em São Paulo.

Como o processo está em andamento, qualquer leitura que se pretenda mais conclusiva é precipitada. Tendo isso em mente, não temos receio de afirmar que a solução construída a partir de um fato imprevisto merece nossa atenção e investimento para futuras edições do Conexão Local. Assim, encaramos essa dupla inter-universitária como uma experiênciapiloto, da qual pretendemos tirar aprendizados para projetarmos, para a próxima edição do Conexão Local, pelo menos uma dupla dentro da lógica de diálogo com outras Instituições de Ensino Superior que têm uma tradição de pesquisa aplicada.

\section{O Programa de Introdução de Pesquisa e os Saberes}

O Programa de Introdução à Pesquisa, no seu sentido mais simples, consolida um conjunto de atividades presentes também em outras universidades e cursos. Sob este aspecto, não há por que buscar destacar suas propriedades específicas. Entretanto para a área de

\footnotetext{
${ }^{9}$ Professores Enock Pessoa, Elaine Correia e Manoel Coracy, da Universidade Federal do Acre
} 
administração e para o contexto específico de Brasil, o projeto Conexão Local e o Programa de Introdução a Pesquisa (PIP) poderia justificar uma certa distinção.

A administração enquanto disciplina acadêmica é fortemente influenciada pelo mundo das grandes organizações e, especificamente, o mundo das empresas. Iniciar uma reflexão sobre administração a partir de experiências exitosas no campo social, oriundas de organizações públicas e organizações sociais muitas vezes de pequeno porte, é demonstrar que talvez há algo para além do universo das organizações que figuram na literatura empresarial. Igualmente, iniciar uma reflexão sobre o porquê da atividade organizativa tendo como foco e exemplo organizações cujos produtos são menos tangíveis do que produtos industrializados ou serviços padronizados é demonstrar que as organizações e os processos de se organizar podem e devem servir para diversos fins e que, mais importante ainda, requer para isso uma sensibilidade a saberes bastante diferentes. Uma das características marcantes, por exemplo, das inscrições feitas para o ciclo de premiação do Programa Gestão Publica e Cidadania é a presença de alianças e parcerias na maioria dos casos; alianças estas que podem ser com outras organizações do setor público, de organizações cívicas ou da sociedade civil, ou ambos os casos (Spink et al, 2002).

Administrar, nestas circunstancias é um processo bastante diferente dos processos administrativos normalmente encontrados nos livros de texto, marcados pela verticalidade do gestor e da subordinação da equipe ao seu líder. De maneira similar, o contexto da atividade e seu foco são também diferentes: voltados às questões sociais urgentes de um país marcado pela desigualdade e necessidade de ação. Saberes aqui são muito menos os saberes codificados das grandes teorias explicativas e muito mais os saberes práticos, e até locais, cuja justificativa se expressa não pela codificação ou a referência bibliográfica, mas pela contribuição à resolução de problemas práticos.

O mesmo ocorre quando o aluno se insere no dia a dia de um centro de pesquisa aplicada, como são os centros de pesquisa na EAESP e nas demais escolas, faculdades e programas membros da ANPAD. O que está em foco é a questão a ser resolvida, seja em um trabalho de assessoria técnica, uma investigação para uma organização específica ou um levantamento geral para publicação sobre um tema urgente e atual. Os centros envolvidos nesta fase foram das áreas de logística, finanças, administração publica e governo, empreendedorismo, tecnologias de informática e governo, terceiro setor e estudos do 
varejo, dando uma boa representatividade da variedade de assuntos que fazem parte do campo administrativo. Aqui, a localidade do saber é menos na sua territorialidade e mais em relação à parte do campo em questão. Entretanto, de novo, é um saber que vem de uma interação específica.

Os saberes das investigações científicas são os saberes dos métodos de investigação, das teorias e da problematização acadêmica, mas também são saberes específicos. Estamos acostumados a considerá-los como saberes centrais ou até especiais mas, vistos a partir do dia a dia, são também saberes localizados num determinado campo, como também os saberes presentes na busca e entrega de documentos, da preparação de gráficos e tabelas e das entrevistas que formam parte das atividades de monitoria.

Quando o Programa de Introdução à Pesquisa foi formulado, havia muita discussão sobre se deve ou não ser considerado como um programa de fases no qual o aluno ou aluna ingressaria na primeira fase (Conexão Local) e procederia até a iniciação científica, assim construindo uma matriz de atividades consolidadas, ou uma progressividade em relação à investigação científica. Decidiu-se a não tornar as fases obrigatórias e permitir aos alunos participar da parte que lhes interessasse, justamente porque o importante era o estimulo à reflexão e o reconhecimento de que conhecimento é construído de maneira diferente em locais diferentes.

Buscou-se, talvez contrapor ao mundo das respostas que caracteriza muito da gestão moderna, um mundo de questões e de indagações, uma relatividade, uma verdade situada e pragmática e não absoluta e certa. Criar uma obrigatoriedade de etapas seria o mesmo que localizar a pesquisa do tipo iniciação cientifica como algo superior às demais formas de atuação, deixar em aberto seria abrir uma série de questões sobre ciência e saberes.

\section{O impacto no processo de repensar a graduação}

Conforme já mencionado, as diferentes atividades que fazem parte do Programa de Introdução à Pesquisa são, cada uma, relativamente simples e até óbvias. Entretanto ao dar visibilidade a elas enquanto conjunto e criar o início de uma cultura na qual o aluno poderia aproveitar aquilo que gostaria de aproveitar enquanto processo de auto-gestão de aprendizagem - em vez da obrigatoriedade dos cursos e dos créditos -, as atividades do 
Programa contribuem para quer as discussões sobre a formatação dos cursos de graduação em administração sejam mais amplas.

Ainda é cedo para poder identificar onde o processo de repensar a graduação terminará, mas já é claro que a introdução do programa ajudou a pensar o curso a partir dos alunos e alunas. O que é estudar administração quando é provável que os únicos contatos que o aluno do primeiro e segundo ano têm com a prática administrativa são, quando muito, produto de pequenos eventos de seu cotidiano enquanto receptora de serviços? Parece, pelo menos após quatro rodadas de Conexão Local, que a experiência de conviver com inovação ajuda a por em perspectivas a própria competência enquanto membro de uma disciplina chamada de Administração assim como a convivência com os centros de pesquisa no período de residência ajuda a reconhecer que por trás do palco científico há também um dia a dia de argumentação e justificação.

No processo de repensar a graduação da EAESP, a idéia de algum tipo de pré-estágio social já se fazia presente na discussão dos primeiros anos e o Conexão Local serviu como campo de provas de sua validade. Além de demonstrar a validade das atividades específicas, o Conexão Local serviu para lembrar os projetistas e reformuladores sobre a importância de uma convivência prática e reflexiva com o campo mais amplo da administração durante os primeiros anos, evitando que este se reduza ao mundo empresarial. Entretanto, ao ser comprovada a validade dessa experiência, um certo paradoxo permanece: como garantir este tipo de experiência para todo os estudantes do curso?

\section{Uma conclusão futura}

A universidade tornou-se um espaço de produção de conhecimento voltado para as necessidades de atores hegemônicos no mercado, quer seja no desenvolvimento de tecnologias voltadas para a produção de bens e criação de serviços, quer seja na formação de profissionais altamente especializados. A universidade contemporânea pode ser caracterizada pela existência de setores onde a prática científica produz conhecimentos dotados de valor apenas para o mercado de bens econômicos. Isto faz com que setores inteiros da universidade se organizem enquanto empresa (Albuquerque, 1980).

Assim, a educação convencional muito raramente se preocupa com o desenvolvimento da pessoa. Opta, normalmente pelo desenvolvimento funcional profissional ou profissional. As 
universidades nasceram como um espaço no qual o mestre formava seus discípulos através da convivência diária. "Esse espaço tornou-se uma grande burocracia em que a convivência é meramente funcional” (Motta, 1986, p. 49).

Tornou se moda no campo da administração discutir organização e aprendizagem, sem que se considerassem os verdadeiros significados das expressões “organizar” e “aprender” que, entendidas no sentido contemporâneo criam o oximoro - contradição em termos “organização de aprendizagem” (Weick \& Westley, 1996). Por outro lado, pouco se lembrou que a universidade é - por definição - uma verdadeira learning organization, ou para utilizar outra expressão em inglês, um house of knowledge. Ser aberto para os saberes oriundos de práticas inovadoras, buscar abrir suas portas para escutar as idéias de atores sociais diferentes, ser sensível para as questões da atualidade na formulação de pesquisas e permitir que todas estas contribuições por sua vez possam se encontrar nas salas de aula e nos seminários, encontros e oficinas, são algo que poucas, se não nenhuma, de nossas instituições de ensino, pesquisa e extensão são capazes de desenvolver (Spink, 1977).

Será que a introdução de um maior leque de oportunidades de pesquisa e de convívio com as questões da atualidade poderia a partir do corpo discente, atingir o corpo docente? Um dos conceitos-pivô de uma parte significativa da pesquisa organizacional - a Teoria Sociotécnica - foi produto de um processo similar; das conversas entre o mineiro e líder sindical Ken Bamforth que passou um período de estágio industrial junto aos pesquisadores do Instituto Tavistock (Spink, 2003). Quem sabe quais conceitos e teorias poderiam estar presentes nas conversas e experiências de quatro anos do projeto Conexão Local? 


\section{Referências Bibliográficas}

ALBUQUERQUE, J. A. G. Instituição e Poder: a análise concreta das relações de poder nas instituições. Rio de Janeiro: Graal, 1980

DOWBOR, L. A Comunidade Inteligente: visitando as experiências de gestão local. In: SPINK, P., CACCIA-BAVA, S.; PAULICS, V.;. Novos contornos da gestão local: conceitos em construção. Instituto Pólis e Programa Gestão Pública e Cidadania/FGVEAESP, São Paulo, 2002.

GEERTZ, C. O Saber Local. Editora Vozes, Petrópolis, 2003.

LACZYNSKI, P. Projeto Escola Família Agroindustrial de Turmalina. In: FARAH, M.F.S. \& BARBOZA, H.B. (Eds) Novas Experiências de Gestão Pública e Cidadania. Rio de Janeiro: Editora Fundação Getulio Vargas, 2000.

LIPSKY, M. Street Level Bureaucracy: Dilemmas of the Individual in Public Services. New York, Russel Sage Foundation, 1980

LOTTA, G \& MARTINS, R. Estudo da Continuidade dos Projetos Educacionais do Município de Icapuí. Cadernos Gestão Pública e Cidadania / CEAPG - Vol. 26. São Paulo: Programa Gestão Pública e Cidadania, 2003.

LOTTA, G. S. Saber e Poder: Agentes Comunitários de Saúde Aproximando Saberes Locais e Políticas Públicas. Dissertação de mestrado apresentada ao Mestrado em Administração Pública e Governo da EAESP/FGV. São Paulo, 2006.

MOTTA, F. C. P. Organização e Poder: Empresa, Estado e Escola. São Paulo: Atlas, 1986

SPINK, P. K, A perda, redescoberta e transformação de uma tradição de trabalho: a teoria sociotécnica nos dia de hoje. Organização e Sociedade, vol.10, n.28, set-dez/2003.

SPINK, P. K. A interação do aluno com o processo de ensino. Revista de Administração de Empresas, v. 17, n.3, pg. 17-21. Fundação Getúlio Vargas, São Paulo, 1977.

SPINK, P., CACCIA-BAVA, S.; PAULICS, V.;. Novos contornos da gestão local: conceitos em construção. Instituto Pólis e Programa Gestão Pública e Cidadania/FGVEAESP, São Paulo, 2002.

WEICK, K. E., \& WESTLEY, F. Organizational Learning: Affirming an Oxymoron. Handbook of Organization Studies. Thousand Oaks, CA: Sage, 1996, pp. 440-458.

Artigo recebido em 03/01/2008 e aceito em 15/03/2008 